\title{
Metabarcoding analysis and fermentation performance of the dominant fungal microbiota associated with the Algerian traditional date product "Btana"
}

\author{
Abdelkader Abekhti $^{1}$ (D) Bernard Taminiau $^{2} \cdot$ Carine Nezer $^{3} \cdot$ Serge Hiligsman ${ }^{4} \cdot$ Kihal Mabrouk $^{5} \cdot$ Georges Daube $^{2}$
}

Received: 5 July 2020 / Revised: 10 February 2021 / Accepted: 16 February 2021

(C) The Author(s), under exclusive licence to Springer Nature Switzerland AG 2021

\begin{abstract}
The study highlights the fungal diversity of the traditional Algerian date's product "Btana" prepared with direct Btana method (DBM) and undirect Btana method (UBM). Btana fungal populations were analyzed through 28S metabarcoding. Data treatment resulted in 122,997 reads representing three Phyla in which $76 \%$ reads (46 OTUs) belong to Ascomycota phylum. Zygosaccharomyces rouxii was the most prevailed species accounting for $35.40 \%$ of the total population. Similarity percentage analysis revealed a low level of resemblance in species in each of the two Btana types (DBM: 17.26\%, UBM: 16.87). According to HPLC analysis, lactate was detected in nine samples within a range of 0.87-23.06 g/100g. Culture plating and subsequent D1/ D2 domain of 28s DNA analysis showed the prevalence of $Z$. rouxii. Fermentation of non-renewed date medium revealed a high ethanol production $(21.31 \pm 2.89 \mathrm{~g} / 100 \mathrm{~g})$ by Lachancea thermotolerans and $5.87 \mathrm{~g} / 100 \mathrm{~g}$ of lactates by Kluyveromyces delphensis. Enzymatic assay revealed a high esterase (C4) and naphtol-AS-BI-phosphohydrolase activity by L. thermotolerans, $K$. delphensis, and Pichia subpelliculosa, while a high level of $\alpha$-fucosidase was recorded for L. thermotolerans and P. subpelliculosa. The current results demonstrated that the traditional date product Btana is a promising source for yeasts useful in production of value-added products like bioethanol and lactic acid using low-income date cultivars.
\end{abstract}

Keywords Dates $\cdot$ Btana $\cdot$ Traditional food $\cdot$ Fermentation $\cdot$ Metabarcoding $\cdot$ Pyrosequencing $\cdot$ Yeasts

\section{Introduction}

Traditional fermented foods constitute a big part of the diet of many populations worldwide. Recently, many projects were undertaken to describe the biological dynamic throughout preparation and during storage (Mokoena et al. 2016; Park

Abdelkader Abekhti

abekhti.aek@univ-adrar.edu.dz; abekhti2008@yahoo.com

1 Department of Life Science and Nature, Laboratory of Natural Saharian Resources, Adrar University, 1001 Adrar, Algeria

2 FARAH, Faculty of Veterinary Medicine, Department of Food Science, University of Liège, Quartier Vallée 2, Avenue de Cureghem, 104000 Liège, Belgium

3 Quality Partner, 62 Rue Hayneux, 4040 Herstal, Belgium

4 3BIO-BioTech, Université Libre de Bruxelles, Brusseles, Belgium

5 Laboratoire de Microbiologie Fondamentale et Appliquée, Faculté des Sciences de la Nature et de la Vie, Université d'Oran 1, 31100 Oran, Algeria et al. 2012). Literature reports a variety of fermented food including those based on fruits and vegetables which contain a diverse microbiome having functional role in controlling organoleptic proprieties and deterioration agents (Abass et al. 2019; Lavefve et al. 2019; Parkouda et al. 2010; Wilfrid et al. 2009). Dates are among these food, which are widely consumed as edible fruits or converted to traditional date by-products to overcome date spoilage (Homayouni et al. 2014). Date's chemical composition delays postharvest degradation owing to the high osmotic pressure induced by high sugar content. Nevertheless, a number of authors have reported cases of microbial spoilage during commercialization of dates and date's products (Siddig 2012). To overcome this, population in southern Algeria transform dates to a traditional fermented product called Btana. Our previous study confirmed that Btana is an interesting method that prevents date spoilage for a period up to 2 years (Abekhti 2015). This product is manufactured according to two methods both inspired by traditional knowledge and have been thoroughly described in our previous study (Abekhti et al. 2013). Briefly, in direct 
Btana method (DBM), soft date fruits like Ghars are directly stacked in plastic bag and containers, whereas in undirect Btana method (UBM), hard date fruits are soften by successive cleaning with water. Technically, like many traditional products, short information is available on the microbial diversity of Btana and the functional role of the predominant communities. Unlike date fruit microbiology which is well documented, no information is available concerning the microbial ecology of the date product Btana (Mehwish et al. 2015; Al-Hazzani et al. 2014; Abdel Moneim et al. 2012; Siddig 2012; Hasnaoui et al. 2010). Our initial investigation (results not published) showed that yeasts are the predominant community and perhaps the main responsible of the organoleptic characteristics of Btana. Likewise, Ould El Hadj et al. (2001) reported that yeasts are involved in spontaneous fermentation of a number of date products like date vinegar produced locally in southern Algerian regions. Within this context, our study is pursued in an attempt to build an understanding of the fungal diversity of Btana. Such data are required to understand the microbiology and biochemistry of the fermentation and its impact on the product quality, and would moreover provide a fundamental basis for developing a future date biotechnology projects. However, the classical approaches used in assessing date microbiota were very restricted due to the limitation and biases associated with the culture-based techniques. Therefore, culture-independent techniques like next-generation sequencing are being widely used with traditional food to fully understand and to predict the evolution of microbial populations within food matrices (Bokulich and Mills 2012; Quince et al. 2009). Pyrosequencing is an NGS technique that will help to get a comprehensive view of the genetic complexity of yeast communities associated with Btana product. We will use this technique along with the isolation and identification of the dominant yeast species investigation of their phenotypes and metabolic products as well as their enzymatic activity. In parallel, we will also investigate the influence of Btana chemical characteristics on the composition of the yeast microbiota.

\section{Material and methods}

\section{Metabarcoding analysis}

To perform pyrosequencing analysis, eight DBM samples were obtained from Ziban-Oued regions $\left(\mathrm{BT}_{1}, \mathrm{BT}_{2}, \mathrm{BT}_{3}\right.$, $\mathrm{BT}_{4}, \mathrm{BT}_{5}, \mathrm{BT}_{6}, \mathrm{BT}_{7}, \mathrm{BT}_{8}$ ) while other three UBM samples were selected from Adrar region $\left(\mathrm{BT}_{9}, \mathrm{BT}_{10}, \mathrm{BT}_{11}\right.$ ) (Fig. 1). The genomic DNA from the Btana pellets was extracted and 28s PCR libraries were generated. Unique multiplex identifiers (barcodes) for each sample were attached to the $5^{\prime}$ end of each primer (NL1 and NL4). Amplification was performed using a Master system gradient apparatus (Eppendorf AG,
Hamburg, Germany) in a final volume of $100 \mu$ l containing 5 U of FastStart high-fidelity polymerase (Roche Diagnostics Belgium NV), $1 \times$ enzyme reaction buffer, $200 \mu \mathrm{m}$ dNTPs (Eurogentec, Belgium), $0.2 \mu \mathrm{m}$ of NL1 and NL4, and $100 \mathrm{ng}$ of genomic DNA. The amplification was performed at $94^{\circ} \mathrm{C}$ for $15 \mathrm{~min}$, followed by 25 cycles at $94^{\circ} \mathrm{C}$ for $40 \mathrm{~s}$, $56^{\circ} \mathrm{C}$ for $40 \mathrm{~s}, 72^{\circ} \mathrm{C}$ for $1 \mathrm{~min}$, and a final elongation step of $7 \mathrm{~min}$ at $72^{\circ} \mathrm{C}$. The final products were ran on a $1 \%$ agarose gel electrophoresis and the visible DNA fragments were extracted and then purified using an SV PCR purification kit (Promega Benelux B.V., Leiden, the Netherlands). The quality of amplicons was cheeked using a PicoGreen doublestranded DNA (dsDNA) quantification assay (Isogen Life Science NV), and then a sequencing was performed using the Roche GS-Junior Genome Sequencer (Roche Diagnostics Belgium NV). Raw data were trimmed and cleaned according to Schloss et al. (2009). Briefly, the sequences were firstly trimmed and sorted according to their multiplex barcode. Then, homopolymeric reads of low quality and those presenting less than $425 \mathrm{bps}$ or containing more than one ambiguous base (Ns) were removed by PyroNoise algorithm (Quince et al. 2009). Furthermore, the potential chimeric sequences were removed by ChimeraSlayer command implemented in MOTHUR pipeline after alignment with the reference database SILVA (Haas et al. 2011). Metabarcoding raw data are available in the NCBI collection under the accession number PRJNA699113: https://trace.ncbi.nlm.nih.gov/ Traces/study/?acc=PRJNA699113.

\section{Strain isolation}

Yeasts associated with the eleven Btana samples were isolated by serial dilution. For that, $25 \mathrm{~g}$ of each sample was transferred into $225 \mathrm{ml}$ of sugar-supplemented alkaline phosphate buffer to prevent osmotic shock and to help recovery of the injured yeasts (Combina et al. 2012). The samples were then homogenized for $10 \mathrm{~min}$ with a Stomacher apparatus. From each sample, $0.1 \mathrm{ml}$ was spread on the surface of yeast glucose chloramphenicol agar plate (YGC; 95765, Sigma). After $24-96 \mathrm{~h}$ of incubation at $25^{\circ} \mathrm{C}$, representative colonies were isolated, subcultured, and examined for purity under a microscope. The isolates were then characterized based on their morphological and physiological properties according to Barnett et al. (2000). Fermentation of sugars (glucose, sucrose, maltose, galactose, and lactose), osmo-tolerance on BHI media containing $50 \%$ and $60 \%(\mathrm{w} / \mathrm{w})$ glucose, and growth on media supplemented with $1 \%$ and $0.5 \%$ of acetic acid and in the presence of $1 \%$ ethanol and methanol were tested. Enzymatic potential was determined by using the commercial API ZYM system, according to the manufacturer's instructions 
Fig. 1 Distribution of fungal families in Btana samples as determined by pyrosequencing analysis

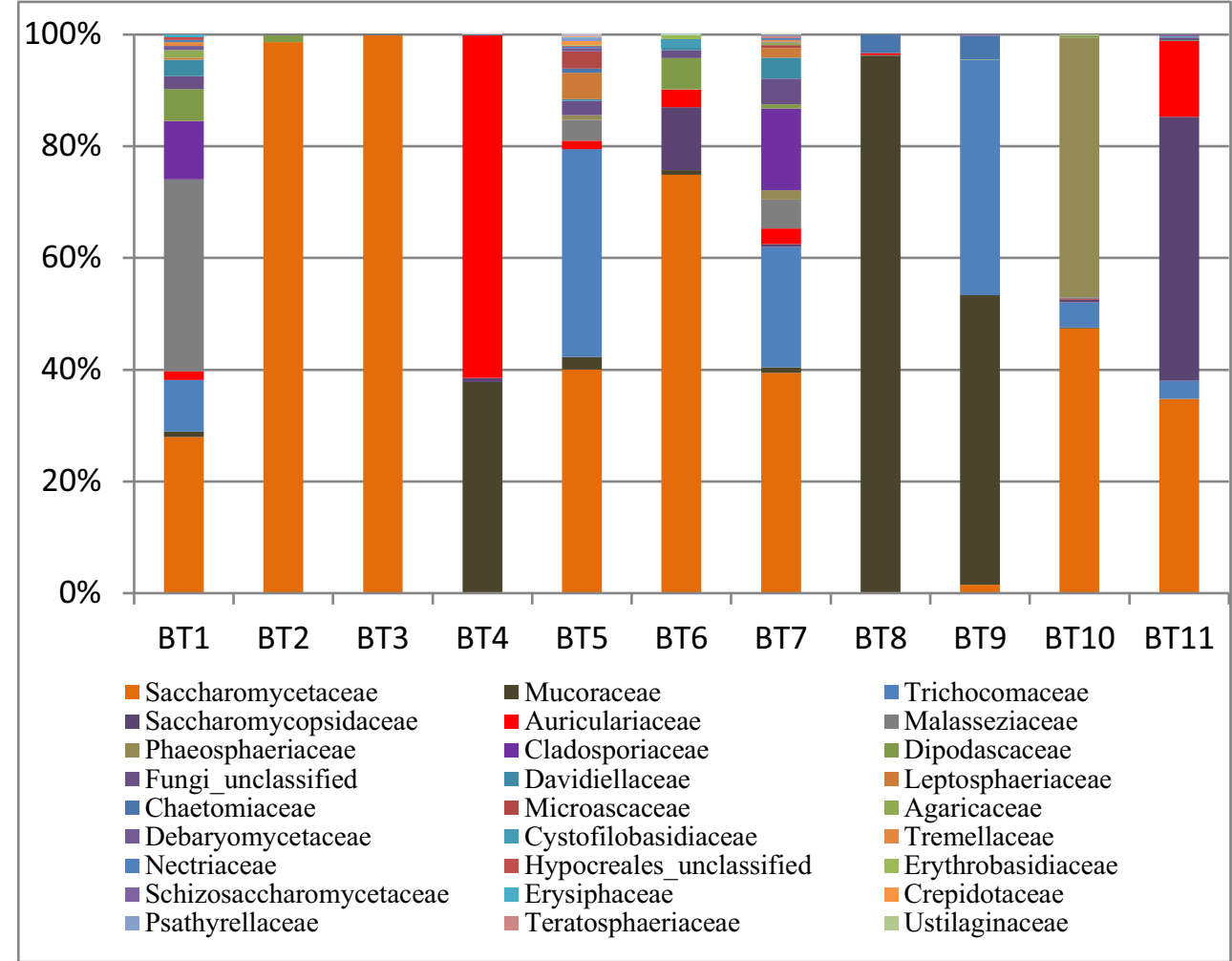

\section{Molecular identification of the yeast strains}

\section{DNA extraction and PCR amplification}

Genomic DNA of yeast strains was extracted using a commercial DNeasy tissue kit (Qiagen) according to the manufacturer's instructions. The DNA templates were then used to amplify the D1/D2 domains of the 28s rDNA usingNL1 (5'-GCAT ATCAATAAGCGGAGGAAAAG-3') and NL4 (5'-GGTC CGTGTTTCAAGACGG-3') primers according to Hesham et al. (2006). The PCR products were purified by the PCR purification kit (Qiagen) and then submitted to sequencing at the GIGA center (Liège University, Belgium). The sequences were manually cleaned and assembled with the DNA Baser Sequence Assembler v4.16 (Heracle BioSoft SRL, www.DnaBaser.com) using default parameters; then, the sequences were aligned with the online GenBank database using the BLASTn program (http://www.ncbi.nlm.nih.gov/BLAST/). Furthermore, a phylogenetic tree was constructed basing on the evolutionary distance between the sequences using the neighbor-joining method and the Kimura 2 parameter in MEGA 5 program (Fig. 2). The tree was then visualized with the TreeView program.

\section{Preparation of date extract and metabolite dosage during fermentation}

Date maceration was made by suspending $500 \mathrm{~g}$ of a freshly prepared Btana into $1000 \mathrm{ml}$ MilliQ water in a Stomacher apparatus. The extract was then sieved through a double layer of muslin cloth and sterilized by autoclaving.

The fermentation assay was performed by inoculating $9 \mathrm{ml}$ of the previous extract with $1 \mathrm{ml}$ of $2 \mathrm{McF}$ arland yeast strain solution. The mixture was incubated at $30^{\circ} \mathrm{C}$ for $48 \mathrm{~h}$ and $96 \mathrm{~h}$, for 15 and 21 days under anaerobic conditions.

At a regular time, a series of tubes were taken along the fermentation period to the $\mathrm{pH}$ which was measured. The fermentation product dosage was carried out by using the HPLC analysis. For that, $5 \mathrm{ml}$ of date extract was centrifuged at $13,000 \mathrm{~g}$ for $10 \mathrm{~min}$, and the supernatant obtained was filtered through a $0.2-\mu \mathrm{m}$ cellulose acetate membrane (Sartorius, Minisart). Dosage of organic acids was made through a standard composed of lyophilized mixture of sodium oxalate, sodium citrate, sodium malate, sodium succinate, sodium formate, and sodium acetate. The standard is supplied as a set of 6 vials. Each vial of the lyophilized mixture is reconstituted in $1.0 \mathrm{ml}$ deionized water prior to use. Glucose, fructose, sucrose, ethanol, formate, acetate, propionate, butyrate, lactate, and succinate were analyzed using an Agilent 1110 series (HP Chemstation software) equipped with a differential refraction index detector (Masset et al. 2010). The HPLC analysis was carried out using a Supelcogel C-610H column preceded by a Supelguard $\mathrm{H}$ precolumn (oven temperature $40^{\circ} \mathrm{C}$ ), $0.1 \%$ $\mathrm{H}_{3} \mathrm{PO}_{4}$ (in MilliQ water) as the isocratic mobile phase at a flow rate of $0.5 \mathrm{ml} \mathrm{min}^{-1}$, and a differential refraction index detector (RID, heated at $35^{\circ} \mathrm{C}$ ). The process lasted for $35 \mathrm{~min}$ at a maximum pressure of 60 bar (Masset et al. 2010). 
Fig. 2 Phylogenetic tree of yeast strains isolated from Btana product prepared according to the neighbor-joining methods using BLAST logarithm

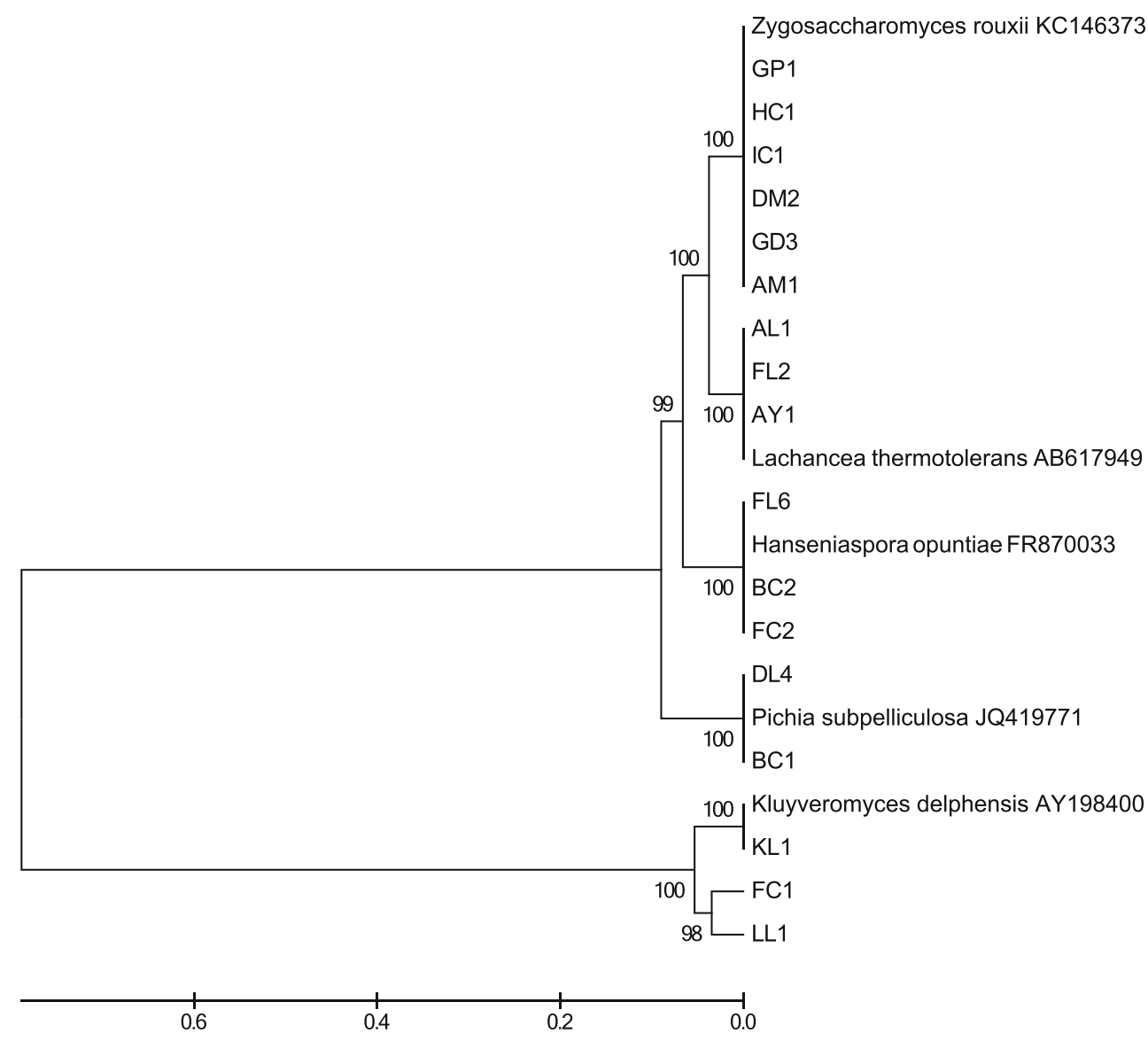

Samples were also analyzed for sugar content and fermentation metabolites as previously reported. All characteristics regarding age, $\mathrm{pH}$, and water activity $\left(a_{\mathrm{w}}\right)$ of the Btana samples were also recorded.

\section{Results and discussion}

Microbial analysis revealed the dominance of yeasts in most samples except for sample BT9. Forty-six (46) yeast strains have been selected and studied. Morphological, biochemical, and physiological characterization allowed the distinction of twenty-three (23) representative strains, which had been assigned to five species according to the similarity in D1/D2 domains of the 28s rDNA, namely Zygosaccharomyces rouxii, Lachancea thermotolerans, Pichia subpelliculosa, Hanseniaspora opuntiae, and Kluyveromyces delphensis (Supplementary Table 1). The predominant isolated species was $Z$. rouxii (9 isolates in Ziban samples (DBM) and one from Adrar-Sali sample (UBM)). This species was frequently isolated from rich sugar food like honey, jam, juice, and sweet marzipan (Solieri et al. 2013, Kurtzman et al. 2011; Carvalho et al. 2006, Martorell et al. 2007). Hanseniaspora opuntiae species was also reported in fruit juices and fermented musts (Nyanga et al. 2013; Cadez et al. 2006). These two species
(Z. rouxii and $H$. opuntiae) were already reported in rotten dates from Abha market (KSA) by Hashem et al. (2014). Even more, L. thermotolerans, P. subpelliculosa, and Kluyveromyces delphensis were commonly isolated from soft drinks, fruit, fruit juices, grapes, raw sugar, and canned vegetables (Deak 2008 and Golubev 2008).

Almost half of the isolated strains belong to the genus Zygosaccharomyces. They are all osmo-tolerant and have been widely isolated from rich sugar products (Barnett et al. 2000). Pyrosequencing data gives a broader picture of the fungal communities in the studied Btana (Fig. 1). Sequence analysis resulted in 122,997 reads after sequence treatment. Overall three Phyla had been detected with around 76\% (46 OTUs) belonging to the Ascomycota phylum. The next phylum Basidiomycota accounted up to $13 \%$ of total sequences (10 OTUs), whereas Zygomycota are presenting $10 \%$ of the total sequences ( 7 OTUs). Two OTUs $(0.77 \%$ of total sequences) remained unclassified. Although Ascomycota were the predominant phylum in most of the samples, Zygomycota were dominant in two samples BT8 (DBM) and BT9 (UBM) and Basidiomycota species outnumbered the other phyla in sample BT4 (DBM). Within Ascomycota, Saccharomycetes were the most abundant class; the highest proportions were detected in BT3 (99.9\%), BT2 (99.88), and BT11 (82.05\%). However, three samples (BT8, BT4, and BT9) presented a 
very low proportion of Saccharomycetes $(0.06,0.87$, and $1.57 \%$ respectively); by contrary, they were dominated by Zygomycetes and polyporoid fruiting fungi, like Agaricomycetes in the case of the sample BT4.

Members of the genus Zygosaccharomyces were dominant though represented by a unique species ( $Z$. rouxii) that was the most prevalent species accounting for $35.40 \%$ of the total population. It was detected in all samples with frequencies varying from 0.04 to $99.98 \%$. This observation confirmed the result of the plate culture and strengthened the usefulness of the metabarcoding approach. The other Saccharomycetes detected by pyrosequencing are Saccharomycopsis fibuligera and Torulaspora delbrueckii with $7.61 \%$ and $7.2 \%$ of total reads respectively. Other species like Pichia kudriavzevii, Pichia kluyveri, and L. thermotolerans were also detected. Nevertheless, these species (except $Z$. rouxii and $L$. thermotolerans) had not been isolated from any of the studied samples by plate cultivation techniques. Furthermore, no reads corresponding to $P$. subpelliculosa, $H$. opuntiae, and $K$. delphensis were detected though already isolated from some Btana samples over this study. By far, members of Eurotiales (Aspergillus, Mucor, Penicillium) were widely detected. Aspergillus oryzae sequences occurred in abundant number in DBM while Aspergillus niger was detected in both Btana types (DBM, UBM). Other filamentous fungi belonging to Mucorales like Rizopus and Mucor were also detected. These fungi were already reported in date postharvest deterioration (Siddig 2012). Regarding fungal population similarity between the two types of Btana, similarity percentage analysis (SIMPER) (Table 1) revealed a low level of yeast population resemblance in both Btana samples (DBM: 17.26\%, UBM: $16.87 \%$ ). Seven (7) OTUs contributed mostly to similarity of DBM samples, with $Z$. rouxii contributing with $60.85 \%$ and Rhizopus stolonifer and Torulaspora delbrueckii by $13.99 \%$ and $4.95 \%$ respectively. Likewise, $Z$. rouxii contributes to the similarity of UBM samples with $90.79 \%$. On the other hand, DBM and UBM samples have $82.98 \%$ dissimilarity average score including all taxa. The other OTUs driving significant differences between the two types of Btana are shown in Table 1. It is noticeable that $R$. stolonifer, T. delbrueckii, Malassezia restricta, Toxicocladosporium sp., Aspergillus oryzae, and Malassezia globosa were mostly found and detected in DBM samples rather than UBM. They contribute by more than $70 \%$ in the discrepancy of DBM from UBM. The observed distinction is due eventually to the disparity in the primary fungal diversity promoted by the origin of date fruits used in Btana preparation. The second explanation comes from the strong selection pressure exerted by the washing step that helps to sweep away a part of the fungi from date fruit during UBM. Only a few taxa remained abundant in these Btana-type numbers like $R$. oryzae, and A. niger.

The values of $a_{\mathrm{w}}, \mathrm{pH}$, sugar content, characteristics of samples, and corresponding selected yeast strains were given in the Supplementary Table 1. Data showed that the total reducing sugars were ranging from 51.3 to $20.82 \mathrm{~g} / 100 \mathrm{~g}$ with the content of glucose being lower than fructose in most samples. In other hand, we observed that Btana samples contain lower sugar content in comparison to date fruit extract; it is rather lower than what had been reported in most date fruits (Abdel Moneim et al. 2012; Hamad et al. 2015; Mortazavi et al. 2010). We also noticed the presence of fermentation byproducts in Btana samples indistinctively which explains that a part of carbohydrate in date fruit was converted into fermentation products by microbial action (Hamad et al. 2015). Therefore, lactate was highly detected within a range of 1.87-23.06 g/100g (Supplementary Table 1). Regarding biochemical tests, results shown in Table 2 indicate that all the species are osmo-tolerant and grow well in 50 and $60 \%$

Table 1 Contribution of the OTUs in Btana samples differentiation

\begin{tabular}{|c|c|c|c|c|c|c|}
\hline \multirow[t]{2}{*}{ Phylotypes (OTUs) } & \multicolumn{2}{|c|}{ Average abundance } & \multirow[t]{2}{*}{ Average dissimilarity } & \multirow{2}{*}{$\begin{array}{l}\text { Dissimilarity standard } \\
\text { deviation }\end{array}$} & \multirow[t]{2}{*}{ Contribution (\%) } & \multirow{2}{*}{$\begin{array}{l}\text { Cumulative } \\
\text { contribution (\%) }\end{array}$} \\
\hline & DBM & UBM & & & & \\
\hline Z. rouxii & 4000.5 & 3846.67 & 21.65 & 1.38 & 26.09 & 26.09 \\
\hline S. fibuligera & 190.63 & 2612 & 11.56 & 0.73 & 13.93 & 40.02 \\
\hline Phaeosphaeria nodorum & 18.25 & 1878 & 8.9 & 0.68 & 10.73 & 50.75 \\
\hline Rhizopus oryzae & 24.75 & 1348.33 & 8.13 & 0.67 & 9.79 & 60.54 \\
\hline Aspergillus niger & 556.13 & 1184 & 7.25 & 0.82 & 8.74 & 69.28 \\
\hline Rhizopus stolonifer & 978.38 & 1 & 6.41 & 0.54 & 7.72 & 77 \\
\hline Torulaspora delbrueckii & 1107.5 & 19 & 4.81 & 0.47 & 5.8 & 82.8 \\
\hline Malassezia restricta & 476.88 & 12.33 & 1.86 & 0.45 & 2.24 & 85.04 \\
\hline Toxicocladosporium & 424 & 0 & 1.77 & 0.56 & 2.13 & 87.17 \\
\hline Aspergillus oryzae & 319.38 & 1 & 1.45 & 0.52 & 1.74 & 88.92 \\
\hline Malassezia globosa & 353.5 & 0.33 & 1.37 & 0.46 & 1.65 & 90.57 \\
\hline
\end{tabular}


glucose broth. Zygosaccharomyces rouxii was the most osmoresistant yeast, which is consistent with an earlier study that had reported that the species can support sugar content as high as $70^{\circ}$ Brix (approximately $875 \mathrm{~g} / 1$ glucose) and is able to grow at water activities as low as 0.60 (Wang et al. 2016; Marvig et al. 2015). It is admitted that this feature of osmotolerance is linked to the production of compatible solutes (i.e., polyols) such as D-arabitol according to many authors (Sharma and Sharma 2017; Evrendilek 2012).

The changes in sugar contents, $\mathrm{pH}$, and other metabolites during the course of the fermentation are presented in Table 3. Accordingly, the date extract contains $64.02 \mathrm{~g} / 100 \mathrm{~g}$ of reducing sugars (glucose and fructose). This value was close to that already reported by Acourene et al. (2014) who has recorded $68.91 \mathrm{~g} / 100 \mathrm{~g}$ in the Hmira variety, the same used in our study. The stress due to sugar concentration in dates imposes a limitation for microbial growth. By comparing metabolism specificity, we found that $Z$. rouxii and $H$. opuntiae had an improved fructose consumption. Similarly, previous studies revealed that $Z$. rouxii is a fructophilic yeast that has a prioritization of fructose transport over that of glucose (Leandro et al. 2014; Leandro et al. 2013; Martorell et al. 2007). Some authors were speculating that the difference in glucose and fructose consumption is due mainly to the metabolic pathway involved (Berthels et al. 2004). In the opposite way, strains belonging to $P$. subpelliculosa used sugars without preference while $L$. thermotolerans and $K$. delphensis utilized preferably glucose. By far, L. thermotolerans exhausted a substantial amount of sugars during the first $48 \mathrm{~h}(37.75 \mathrm{~g} / 100 \mathrm{~g})$. This pattern continues until the end of the fermentation (21 days) to reach $56.55 \mathrm{~g} / 100 \mathrm{~g}$ of sugars consumed. Decreasing of $\mathrm{pH}$ below 5 within the first 48 is another common feature of fermentation that decreases further over the following period until 15 days when thereafter it remains constant. Kluyveromyces delphensis strains showed a markedly $\mathrm{pH}$ decrease (1.73 units), whereas $P$. subpelliculosa strains were the less acidifying ( 0.77 units). In general, the fermentation pattern of the yeasts presented approximately the same profile with ethanol being the dominant product although there was a slight fluctuation regarding the final products. In other hand, some authors emphasize that the yeasts isolated from high sugar environment have unusual physiological characteristics that might increase production of ethanol and other metabolic products (Tan et al. 2015). Accordingly, a substantial amount of carbon fraction ${ }^{1}$ was converted to metabolic product (ethanol, lactate, acetate, formate, and succinate). Other carbon fractions were used to produce carbon dioxide and to generate new yeast cells (Hiligsmann et al. 2011). Ethanol was yielded as almost as $50 \%$ of the used carbon molar fraction (C-mol) from the total sugar (Supplementary Table 2) except

\footnotetext{
${ }_{1}^{1}$ Fermentation products were transformed into molar carbon fractions to calculate carbon conversion balance as shown in Supplementary Table 2.
}

P. subpelliculosa strains which produced a low amount of ethanol $(7.42 \pm 0.63 \mathrm{~g} / 100 \mathrm{~g} / 16.63 \%$ of C-mol). By $96 \mathrm{~h}$, $L$. thermotolerans yielded the higher amount of ethanol $(21.31 \pm 2.89 \mathrm{~g} / 100 \mathrm{~g}$ of dates $)$ approaching the yield recorded for Saccharomyces cervisiaeon sorghum (25 g/100g) and apple pomace (19.0 g/100 g) (Parmar and Rupasinghe 2013; Salvi et al. 2009). Other studies confirmed our observation and emphasized that $L$. thermotolerans is a potent ethanolproducing yeast associated with fruits, fruit jams, and high sugar food (Freel et al. 2014). Recently, this species has also been used for production of valuable compounds like sophorolipid surfactants (Mousavi et al. 2015). Regarding ethanol resistance, only $P$. subpelliculosa strains were able to sustain high ethanol, whereas $Z$. rouxii strains showed a poor tolerance of acidity in the presence $0.5 \%$ of acetic acid. So far, the viability at the end of the fermentation period was remarkable for all species except $Z$. rouxii strains. The viability feature is a key element for biotechnological process involving recycling or re-circulation. In this respect, Wang et al. (2016) reported that non-Saccharomyces species found in fermented food could be isolated only from the early stages of fermentation. Therefore, the studied strains isolated from Btana are promising candidates in fermentation process as they can sustain under extended periods of fermentation and high ethanol stress. Also, we noticed the formation of a versatile array of organic acids throughout the fermentation course. Pichia subpelliculosa was the most efficient in lactate production $(40.03 \pm 9.88 \%)$ according to the carbon balance and further was the sole yeast able to produce formate during the first $48 \mathrm{~h}$. After 96 h, metabolite concentrations decreased slightly except $K$. delphensis for which we have recorded a decline in ethanol production in favor of a significant increase in lactate (5.26-5.62 g/100g). Furthermore, at this stage, an increase of formate was recorded for most strains except $K$. delphensis. In addition to metabolite assessment, the estimation of the dry cell biomass (result no published) indicated that $K$. delphensis produces more biomass $(0.425 \mathrm{~g} / \mathrm{l})$ than the other species including the commercial strain $S$. cerevisiae $(0.375 \mathrm{~g} / 1)$. Interestingly, many authors reported that Kluyveromyces species have a higher $\mu_{\max }$ value and a shorter lag phase which is translated into a higher biomass production compared to S. cerevisiae (Lane and Morrissey 2010). This might be due to the natural osmo-tolerance ability of $K$. delphensis that was primarily isolated from sugary deposits on dried figs (Lane and Morrissey 2010).

\section{Determination of enzymatic profile}

In order to investigate the eventual functional role of the selected strains, we have compared their fermentation profile and enzymatic activity. The data obtained with API-ZYM system showed significant differences in the nature and the amount of the released enzymes (Table 4). $\beta$-glucosidase 


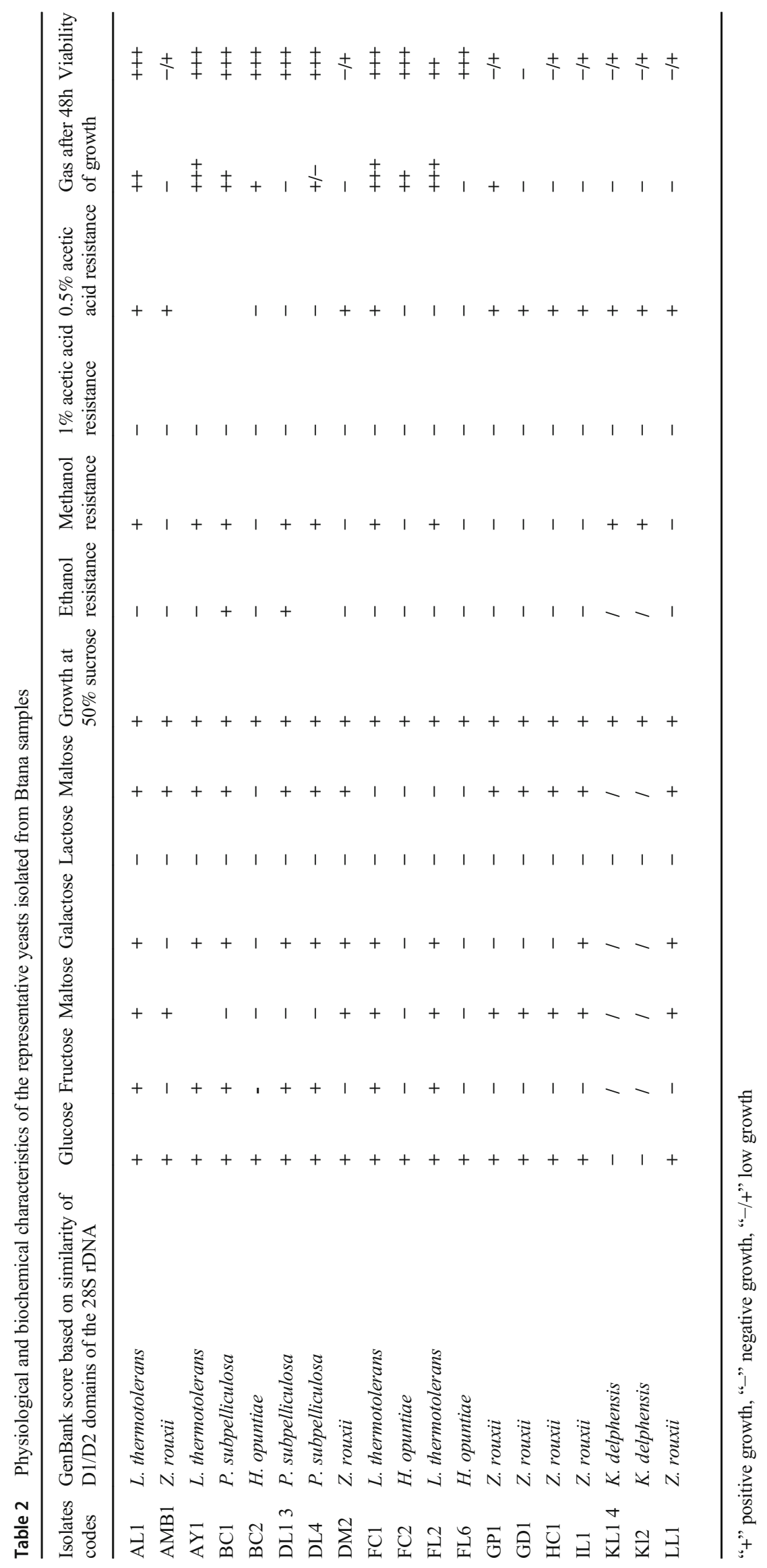




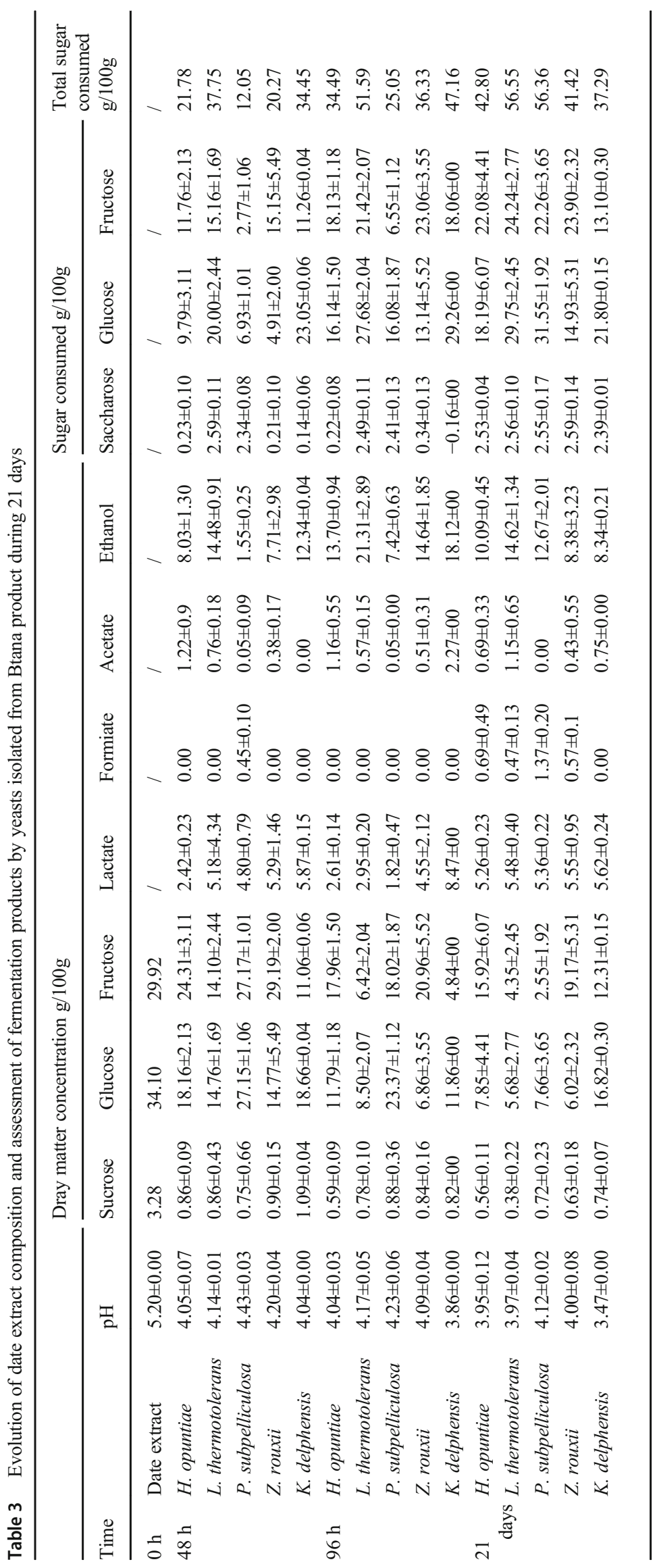


Table 4 Results of API ZYM test of the isolated yeasts

\begin{tabular}{|c|c|c|c|c|}
\hline Enzymatic activity tested & L. thermotolerans & Z. rouxii & P. subpelliculosa & K. delphensis \\
\hline Alkaline phosphatase & 1 & 0 & 2 & 0 \\
\hline Esterase C4 & 5 & 2 & 5 & 5 \\
\hline Esterase lipase C8 & 3 & 2 & 5 & 3 \\
\hline Lipase C14 & 3 & 2 & 3 & 3 \\
\hline Leucine arylamidase & 1.5 & 1 & 1 & 1.5 \\
\hline Valine arylamidase & 2 & 3 & 2 & 2 \\
\hline Cystine arylamidase & 2 & 1 & 2 & 2 \\
\hline Trypsin N-benzoyl & 0 & 0 & 0 & 0 \\
\hline Chymotrypsin & 0 & 0 & 0 & 0 \\
\hline Phosphatase & 0 & 0 & 0 & 0 \\
\hline Naphtol-AS-BI-phosphohydrolase & 5 & 3 & 5 & 5 \\
\hline$\alpha$-Galactosidase & 1 & 2 & 2 & 1 \\
\hline$\beta$-Galactosidase & 0 & 0 & 0 & 1.5 \\
\hline$\beta$-Glucuronidase & 0 & 0 & 0 & 0 \\
\hline$\alpha$-Glucosidase & 0 & 0 & 0 & 1.5 \\
\hline$\beta$-Glucosidase & 5 & 5 & 3 & 0 \\
\hline $\mathrm{N}$-acetyl--glucosaminidase & 3 & 0 & 5 & 0 \\
\hline$\alpha$-Mannosidase & 0 & 0 & 0 & 0 \\
\hline$\alpha$-Fucosidase & 3 & 1 & 4 & 2.5 \\
\hline
\end{tabular}

enzyme was expressed by all strains except one strain belonging to $Z$. rouxii and $K$. delphensis that instead expressed $\alpha$ glucosidase and $\beta$-galactosidase exclusively. As regards $\mathrm{N}$ acetyl-glucosaminidase enzyme, it was detected for $L$. thermotolerans and P. subpelliculosa. Moreover, these two species demonstrated a high activity of $\alpha$-fucosidase. However, an interesting finding was observed for L. thermotolerans which expressed a high glucosidase activity that might be the origin of the observed low $\mathrm{pH}$ in date extract and can also explain the high amount of lactates detected in samples in which the yeast was predominant (Tokuhiro et al. 2008). In other hand, the $\beta$-glucosidase activity marks a strong ability to hydrolyze poly-glucose sugars with $\alpha$ - or $\beta$-linkages like cellulose, 1-3 and 1-4 $\beta$-glucans or xyloglucans present in date fruit wall, and other antinutritive glucose compounds containing hemicelluloses (Simon 2008). Furthermore, it was reported that $\beta$-glucosidase is a key enzyme in alcohol production process from orange, peach, strawberry, cherry, and other fruit juices (Arrizon et al. 2011). Furthermore, we noticed that Kluyveromyces strains produced highly $\beta$-galactosidase and being so interesting in lactose hydrolysis into lactate (Romo-Sánchez et al. 2010).

The proteolytic activity linked to $\alpha$-mannosidase, chymotrypsin, phosphatase, and trypsin N-benzoyl was not detected for any of the species, whereas leucine arylamidase, valinearylamidase, and cystineary lamidase were recorded at a very low level. By contrast, an interesting lipolytic activity of esterase (C4), esterase lipase (C8), lipase (C14), and
naphtol-AS-BI-phosphohydrolase was recorded. Lachancea thermotolerans, $K$. delphensis, and P. subpelliculosa were noticeably characterized by high esterase (C4) and naphtolAS-BI-phosphohydrolase activities. On the other hand, arylamidases (aminopeptidases) were recorded at a low extent indicating a limiting yeast proteolytic activity, which can be easily explained by the poor protein content of dates (Dodor and Tabatabai 2007).

\section{Conclusion}

This study highlights the advantage of next-generation sequencing technique in the determination of the fungal diversity of the traditional date product "Btana" produced in South Algeria. Both culture-dependent and independent techniques provided full details of the identity of the dominant species within the population structure. The osmo-tolerant yeast $Z$. rouxii was the most dominant in both Btana types (DBM and UBM) and many isolates belonging to this species were identified in most samples. Further investigation showed that only few taxa were found significantly different between the samples. The change was much marked in terms of species representation rather than in abundance. The most distinctive feature of DBM is the presence of the filamentous fungi mainly (Rhizopus and Aspergillus) comparing to the UBM that undergoes a washing step which reduces drastically the load of this population. Biochemical and enzymatic proprieties 
provided relevant information about the characteristics of the isolated yeasts in the Btana product, mainly their high osmotolerance. Furthermore, the study of the enzymatic activity revealed that most yeasts harbor the ability of the degradation of several carbohydrates present in the Btana product. In the matter of fermentation performance, the species L. thermotolerans converts more date's sugars to ethanol while $K$. delphensis and $P$. subpelliculosa produced more lactates. Also, it is noteworthy to state that the recorded data were obtained in static conditions besides any regulation or nutrient supplementation throughout the fermentation process. The current results might be useful for providing to the biotechnology field, active yeasts with high sugar resistance to develop value-added products like ethanol and lactic acid using low-income date cultivars and other phoenicical biomass in South Algerian regions.

Supplementary Information The online version contains supplementary material available at https://doi.org/10.1007/s10123-021-00166-0.

Acknowledgements The authors acknowledge Pr. Sebaihia and Dr. Djebbar Abla of the Laboratory of Molecular Biology, Genomics, and Bioinformatics, from the University Hassiba Benbouali of Chlef(Algeria) for their valuable comments and their constructive remarks and revision of the previous version of this manuscript.

\section{References}

Abass AB, Adegoke GO, Awoyale W, Gaspar A, Mlingi N, Andrianavalona V, Randrianarivelo R, Sulyok M, Mneney A, Ranaivoson LR (2019) Enumeration of the microbiota and microbial metabolites in processed cassava products from Madagascar and Tanzania. Food Control 99:164-170

Abdel Moneim E, Sulieman IA, Elhafise AA, Abdelrahim M (2012) Comparative study on five Sudanese date (Phoenix dactylifera L.) fruit cultivars. Food Nutr Sci 3:1245-1251

Abekhti A, Zarour K, Boulal A, Benmechernen Z, Kihal M (2013) Evaluation of microbiological quality of the date fruit product "Btana" produced in Adrar South Algeria. J Microbiol Res 3(5): $163-170$

Abekhti A, Taminiau B, Kihal M, Daube G (2015) Metagenomic analysis of the bacterial microbiota linked to the traditional Algerian date product "Btana". Ann Microbiol 65:2415-242

Acourene S, Djafri K, Benchabane A, Tama A, Taleb B (2014) Dates quality assessment of the main date palm cultivars grown in Algeria. AnnResRev Biol 4:487-499

Al-Hazzani AA, Shehata AI, Moubayed NMS, Al Houri HJ (2014) Antimicrobial and biochemical properties of selected edible brown and red marine macroalgae. J Pure ApplMicrobio 8:1275-1282

Arrizon J, Mateos JC, Sandoval G, Aguilar B, Solis J, Aguilar MG (2011) Bioethanol and xylitol production from different lignocellulosic hydrolysates by sequential fermentation. J Food Process Eng 35:437454

Barnett JA, Payne RW, Yarrow D (2000) Yeasts: characteristics and identification, 3rd edn. Cambridge. Universit Press, Cambridge
Berthels NJ, Cordero-Otero RR, Bauer FF, Thevelein JM, Pretorius IS (2004) Discrepancy in glucose and fructose utilization during fermentation by Saccharomyces cerevisiae wine yeast strains. FEMS YeastRes 4:683-689

Bokulich NA, Mills DA (2012) Next-generation approaches to the microbial ecology of food fermentations. BMB 45:377-389

Cadez N, Rasper P, Smith MT (2006) Phylogenetic placement of Hanseniaspora-Kloeckera species using multigene sequence analysis with taxonomic implications: descriptions of Hanseniaspora pseudoguilliermondii sp. nov. and Hanseniaspora occidentalisvar. citrica var. nov. Int JSystEvolMicr 56:1157-1165

Carvalho MC, Rocha A, Estevinho L, Choupina AB (2006) Identification of honey yeast species based on RELP analyses of the ITS region. CiencTecnol Aliment 5:11-17

Combina M, Pérez-Torrado R, Tronchoni J, Belloch C, Querol A (2012) Genome-wide gene expression of natural hybrid between Saccharomyces cerevisiae and S. kudriavzevii under enological conditions. Int J Food Microbiol 157:340-345

Deak T (2008) Handbook of food spoilage yeasts. CRC Press

Dodor DE, Tabatabai MA (2007) Arylamidase activity as an index of nitrogen mineralization in soils. Communications in Soil Science and Plant Analysis 8:2197-2207

Evrendilek GA (2012) Sugar alcohols (polyols). In: Varzakas T (ed) Sweeteners: nutritional aspects, applications, and production technology. CRC Press, pp 45-78

Freel KC, Friedrich A, Hou J, Schacherer J (2014) Population genomic analysis reveals highly conserved mitochondrial genomes in the yeast species Lachancea thermotolerans. Genome Biol Evol 6: 2586-2594

Haas BJ, Gevers D, Earl AM, Feldgarden M, Ward DV, Giannoukos G, Ciulla D, Tabbaa D, Highlander SK, Sodergren E, Methe B, DeSantis TZ, The Human Microbiome Consortium, Petrosino JF, Knight R, Birren BW (2011) Chimeric 16S rRNA sequence formation and detection in Sanger and 454-pyrosequenced PCR amplicons. Genome Res 21:494-504

Hamad I, Hamada A, Al Jaouni S, Gaurav Z, Han A, Sherif H, Momtaz Hegab M, Hagagy N, Selim S (2015) Metabolic analysis of various date palm fruit (Phoenix dactylifera L.) cultivars from Saudi Arabia to assess their nutritional quality. Molecules:13620-13641

Hashem M, Hesham AEL, Alrumman SA, Alamri SA, Moustafa MFM (2014) Indigenous yeasts of the rotten date fruits and their potentiality in bioethanol and single-cell protein production. Int J agric Biol 16:752-758

Hasnaoui A, Elhoumaizi MA, Asehraou A, Hakkou A (2010) Chemical composition and microbial quality of main varieties of dates grown in Figuig oasis of Morocco. Int J Agric Biol 12:311-314

Golubev WI (2008) Taxonomical, ecological, and geographical diversity of yeast cultures in the All-Russia Collection of Microorganisms (VKM). Appl Biochem Microbiol 44:84-88

Hesham A, Wang Z, Zhang Y, Zhang J, Lu W, Yang M (2006) Isolation and identification of a yeast strain capable of degrading four and five ring aromatic hydrocarbons. AnnMicrobiol 56:109-112

Hiligsmann S, Masset J, Hamilton C, Beckers L, Thonart P (2011) Comparative study of biological hydrogen production by pure strains and consortia of facultative and strict anaerobic bacteria. Bioresour Technol 102:3810-3818

Homayouni A, Azizi A, Khodavirdivand KA, Amini A, Eslam A (2014) Date canning: a new approach for the long-time preservation of date. J Food Sci Technol 52:1872-1880

Kurtzman C P, Fell JW, Boekhout T (2011) The yeasts, a taxonomic study (5th ed). Amsterdam: Elsevier

Lane MM, Morrissey JP (2010) Kluyveromyces marxianus: a yeast emerging from its sister's shadow. Fungal Biol Rev 24:17-26

Lavefve L, Marasini D, Carbonero F (2019) Microbial ecology of fermented vegetables and non-alcoholic drinks and current 
knowledge on their impact on human health. Adv Food Nutr Res 87: $47-185$

Leandro MJ, Sychrová H, Prista C, Loureiro-Dias MC (2013) ZrFsy1, a high-affinity fructose/H+ symporter from fructophilic yeast Zygosaccharomycesrouxii. PLoS ONE8: e68165. https://doi.org/ 10.1371/journal.pone.0068165

Leandro MJ, Cabral S, Prista C, Loureiro-Dias MC, Sychrová H (2014) The high capacity specific fructose facilitator ZrFfz1 is essential for the fructophilic behavior of Zygosaccharomyces rouxii CBS 732T. Eukaryot Cell 13:1371-1379

Martorell P, Stratford M, Steels H, Fernández-Espinar MT, Querol A (2007) Physiological characterization of spoilage strains of Zygosaccharomyces bailii and Zygosaccharomyces rouxii isolated from high sugar environments. Int J Food Microbiol1 14:234-242

Marvig CL, Kristiansen RM, Nielsen DS (2015) Growth/no growth models for Zygosaccharomyces rouxii associated with acidic, sweet intermediate moisture food products. Int J Food Microbiol 192:5170

Masset J, Hiligsmann S, Hamilton C, Beckers L, Franck P, Thonart P (2010) Effect of $\mathrm{pH}$ on glucose and starch fermentation in batch and sequenced-batch mode with a recently isolated strain of hydrogenproducing Clostridium butyricumCWBI1009. Int J Hydrog Energy 35:3371-3378

Mehwish I, Beenish S, Roheena A, Afshan K, Shagufta N (2015) Effect of $\gamma$-irradiation doses on the sensory and microbial quality of dates (Phoenix dactylifera). Biologia (Pakistan) 61:227-233

Mokoena MP, Mutanda T, Olaniran AO (2016) Perspectives on the probiotic potential of lactic acid bacteria from African traditional fermented food and beverages. J Food Nutr Res 60. https://doi.org/ 10.3402/fnr.v60.29630

Mortazavi SMH, Arzani K, Barzegar M (2010) Analysis of sugars and organic acids contents of date palm (Phoenix Dactylifera L.) 'Barhee' during fruit development. Acta Hortic 882:793-801

Mousavi F, Beheshti-Maal K, Massah A (2015) Production of sophorolipid from an identified current yeast, Lachancea Thermotolerans BBMCZ7FA20, isolated from honey bee. Curr Microbiol 71:303-310

Nyanga LK, Gadaga TH, Nout MJR, Smid EJ, Boekhout T, Zwietering MH (2013) Nutritive value of masau (Ziziphus mauritiana) fruits from Zambezi Valley in Zimbabwe. Food Chem 138(1):168-172

Ould El Hadj MD, Sebihi AH, Siboukeur O (2001) Qualité hygiénique et caractéristiques physicochimiques du vinaigre traditionnel de quelques variétés de dattes de la cuvette de Ouergla. Rev Energ Ren.: Production et valorisation Biomasse 87-92

Park EJ, Chun J, Cha CJ, ParkWS JCO, Bae JW (2012) Bacterial community analysis during fermentation of ten representative kinds of kimchi with barcoded pyrosequencing. FoodMicrobiol 30:197-204

Parkouda C, Thorsen L, Compaoré CS, Nielsen DS, Tano-Debrah K, Jensen JS, Diawara B, Jakobsen M (2010) Microorganisms associated with Maari, a Baobab seed fermented product. International Journal of Food Microbiology 142(3):292-301

Parmar I, Rupasinghe HPV (2013) Bio-conversion of apple pomace into ethanol and acetic acid: enzymatic hydrolysis and fermentation. Bioresour Technol 130:613-620

Quince C, Lanzen A, Curtis TP (2009) Accurate determination of microbial diversity from 454 pyrosequencing data. Nat Methods 6:639641

Romo-Sánchez S, Alves-Baffi M, Arévalo-Villena M, Úbeda-Iranzo J, Briones-Pérez A (2010) Yeast biodiversity from oleic ecosystems: study of their biotechnological properties. FoodMicrobiol 27:487492

Salvi S, Castelletti S, Tuberosa R (2009) An updated consensus map for flowering time QTLs in maize. Maydica 54:501-512

Schloss PD, Westcott SL, Ryabin T, Hall JR, HartmannM HEB, Lesniewski RA, Oakley BB, ParksDH RCJ, SahlJW SB, ThallingerGG VHDJ, Weber CF (2009) Introducing mothur: open-source, platform-independent, community-supported software for describing and comparing microbial communities. Appl Environ Microbiol 75:7537-7541

Sharma A, Sharma SC (2017) Physiological basis for the tolerance of yeast Zygosaccharomyces bisporus to salt stress. Hayati J Biosci 24:176-181

Siddig HH (2012) The microbial quality of processed date fruits collected from a factory in Al-Hofuf City, Kingdom of Saudi Arabia. Emir J Food Agr 24:105-112

Simon O (2008) Verdauung und Resorption. In: Jeroch H, Drochner W, Simon O (eds) Ernährun gland wirtschaftlicherNutztiere, 2nd edn. Eugen Ulmer, Stuttgart, pp 109-133 (in German)

Solieri L, Dakal TC, Croce MA, Giudici P (2013) Unraveling genomic diversity of the Zygosaccharomyces rouxii complex with a link to its life cycle. FEMSYeast Res 13:245-258

Tan D X, Manchester LC, Esteban-Zubero E, Zhou Z, Reiter RJ (2015) Melatonin as a potent and inducible endogenous antioxidant synthesis and metabolism. Molecules 20:18886-18906

Tokuhiro K, Ishida N, Kondo A, Takahashi H (2008) Lactic fermentation of cellobiose by a yeast strain displaying beta-glucosidase on the cell surface. Appl Microbiol Biotechnol 79:481-488

Wang H, Hu Z, Long F, Guo C, Niu C, Yuan Y, Yue T (2016) The effects of stress factors on the growth of spoilage yeasts isolated from applerelated environments in apple juice. J Food Saf 36:162-171

Wilfrid PS, Nielsen DS, Hounhouigan JD, Thorsen L, Nago MC, Jakobsen M (2009) The microbiota of Lafun, an African traditional cassava food product. Int J Food Microbiol 133(1-2):22-30

Publisher's note Springer Nature remains neutral with regard to jurisdictional claims in published maps and institutional affiliations. 